Int. J. Environ. Res. Public Health 2006, 3(4), 338-342

International Journal of

Environmental Research and Public Health

ISSN 1661-7827

www.jijerph.org

(c) 2006 by MDPI

\title{
Health Benefits of Geologic Materials and Geologic Processes
}

\author{
Robert B. Finkelman \\ U.S. Geological Survey, Mail Stop 956, Reston, VA 20192 USA and Ulli G. Limpitlaw, Earth Sciences, University of Northern \\ Colorado, Greeley, CO 80639, USA \\ *Correspondence to Dr. Robert B. Finkelman. E-mail: rbf@usgs.gov
}

Received: 15 June 2005 / Accepted: 10 October 2006 / Published: 31 December 2006

\begin{abstract}
The reemerging field of Medical Geology is concerned with the impacts of geologic materials and geologic processes on animal and human health. Most medical geology research has been focused on health problems caused by excess or deficiency of trace elements, exposure to ambient dust, and on other geologically related health problems or health problems for which geoscience tools, techniques, or databases could be applied. Little, if any, attention has been focused on the beneficial health effects of rocks, minerals, and geologic processes. These beneficial effects may have been recognized as long as two million years ago and include emotional, mental, and physical health benefits. Some of the earliest known medicines were derived from rocks and minerals. For thousands of years various clays have been used as an antidote for poisons. "Terra sigillata," still in use today, may have been the first patented medicine. Many trace elements, rocks, and minerals are used today in a wide variety of pharmaceuticals and health care products. There is also a segment of society that believes in the curative and preventative properties of crystals (talismans and amulets). Metals and trace elements are being used in some of today's most sophisticated medical applications. Other recent examples of beneficial effects of geologic materials and processes include epidemiological studies in Japan that have identified a wide range of health problems (such as muscle and joint pain, hemorrhoids, burns, gout, etc.) that may be treated by one or more of nine chemically distinct types of hot springs, and a study in China indicating that residential coal combustion may be mobilizing sufficient iodine to prevent iodine deficiency disease.
\end{abstract}

Key words: Health benefits, rocks, minerals, trace elements, coal combustion, hot springs.

\section{Introduction}

Medical geology - the impacts of geologic materials and geologic processes on animal and human health - has been enjoying resurgence in recent years. Several books on this subject have been published within the past few years [1-3], numerous articles on medical geology have appeared in various journals [4-12] and a number of symposia [13] have been devoted to this topic. Nearly all of these books, articles and symposia have focused on the health problems caused by geologic materials such as exposure to elements such as arsenic, mercury, lead, fluorine, selenium, and uranium; minerals such as asbestos, quartz, pyrite; and geologic processes such as earthquakes and volcanic eruptions. The list of geologic materials and geologic processes that adversely impact human health seems endless. However, there is a kinder, gentler side of nature.

Although relatively little acknowledgement has been given to the health benefits provided by geologic materials and processes [14], there is a long, rich and varied record of these benefits. This is not new knowledge; rather it is knowledge that has, to some degree been lost. It has been pushed aside for a more "modern" way of healing. As tribes and languages die out, knowledge of the ways minerals, fossils, and rocks were used to cure vanishes [15]. Awareness of the beneficial health effects of rocks and minerals may have occurred more than two million years ago. Abrahams [16] cites the discovery of powdered clays at a homo habilis site in Africa that is about two million years old. The most logical explanation is that these 
early humanoids used the powdered clays to aid in digestion or as an antidote for upset stomachs - the same uses that these clays are put to today! For eons primitive tribes throughout the world have used various types of clays for nutritional and therapeutic purposes [17]. As long as three to five thousand years ago, ancient civilizations (Mesopotamia, China, India, Egypt, etc.) used minerals for their therapeutic value. "Terra sigillata," (earth that has been stamped with a seal) was described in the first century AD [16] and may have been the first patented medicine (Figure 1).
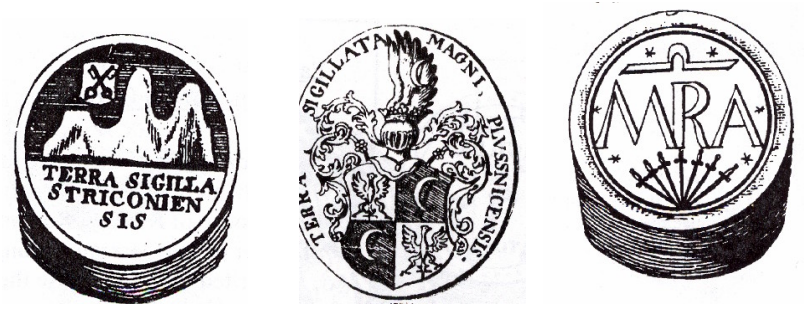

Figure 1: Terra Sigillata; Adapted from Reinbacher (2003).

The health benefits of geologic materials and processes can be organized into several broad categories:

- $\quad$ Source of essential nutrients

- Pharmaceuticals and health care products

- Hot springs and geysers

- Talismans and amulets

This paper will briefly discuss these health benefits providing a few examples from each category. It is not our intention to offer a comprehensive discussion of the health benefits. The purpose of this paper is to provide the readers with an awareness of this oft neglected aspect of medical geology.

\section{Source of Essential Nutrients}

All living organisms require certain naturally occurring elements (essential nutrients) for their metabolism to function efficiently. For humans there are 14 elements that are believed to be essential. These are: calcium, chromium, copper, fluorine, iodine, iron, magnesium, manganese, molybdenum, phosphorus, potassium, selenium, sodium and zinc [17]. The ultimate source of these elements is the natural environment. From the dawn of time human beings have obtained the essential nutrients by eating plants that accumulated these elements from the soil; by eating meat from animals that accumulated the elements from plants or from animals that had obtained the elements from plant eating organisms lower in the food chain; by drinking water in which the nutrients are suspended or dissolved; or by directly ingesting soil (Geophagea). Today many people rely on vitamin pills to augment their daily requirements of the essential elements but the elements in vitamin pills are ultimately derived from rocks, minerals, or natural waters.
Geophagy or geophagea is a Greek word meaning "eating earth". It refers to the practice of people in almost every society to eat soil as part of their diet (Figure 2). Pica is a similar term that is commonly applied to the tendency of children to intentionally eat unnatural substances such as soil. The craving to eat soil, principally clay, may be physiological in nature or may have derived from observation of animals that eat soil, clay, pebbles, etc. Soil may constitute 10 percent or more of what grazing animals ingest [16]. Certain birds are known to ingest clays prior to eating toxic fruits. The clays apparently act to detoxify the fruits. In Africa, wild yams, an important source of nutrients during time of famine, can be eaten if detoxified through ingestion of clay [16]. American Indians have also been known to mix soil with acorns, tubers, and berries to render them edible.

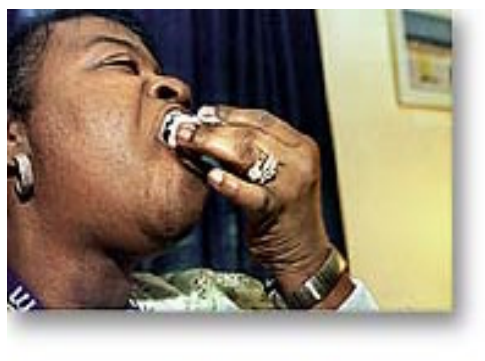

(a)

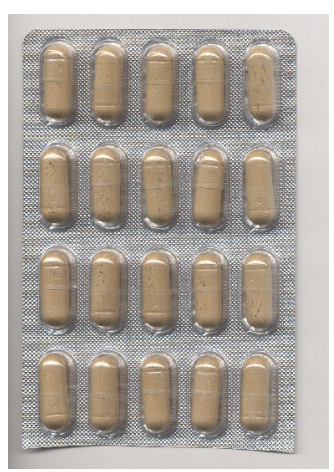

(b)
Figure 5: a) Eating clay; b) Loesss (wind-blown sand) pills produced in Germany.

There is no question that people who eat unprocessed soil are at risk for several significant health problems (exposure to harmful levels of chemical elements, exposure to soil pathogens, intestinal blockages, etc.). There is, however, a lively debate as to whether there are other health benefits derived from geophagy. Reinbacher [18] uses the term 'geopharma' - eating earth as a medicine for this facet of geophagy. Several hypotheses have been proposed for the heath benefits of geophagy. The most commonly cited benefit is that the soil provides essential nutrients. In Africa and elsewhere, pregnant woman commonly eat red clays. The iron in these clays that may offset iron-deficiency associated with the pregnancy. There is a question as to whether the iron in these clays is bioavailable. The calcium in soils and minerals are also believed to aid in lactation of nursing women [16].

Reinbacher [18] suggests that eating clay may augment an insufficient food supply, thus staving off the feeling of hunger (Figure 2). He cites workers in Germany who used 'stone butter', talc, on their lunch sandwiches. There are also reports that ingesting clay may cure certain diseases. He cites the example of people in Cameroon who eat baked clay to cure hookworm.

There is general agreement that ingestion of clays can cure certain stomach disorders such as stomachaches, acid indigestion, nausea, and diarrhea. Kaolin and smectitic 
clays are the principle ingredients in some of the most commonly used products for treating stomach disorders. There are many books [19, for example] that advocate eating clay as a safe and effective way to detoxify, aid digestion, relieve nausea, treat allergies, soothe ulcers, counteract poisoning, etc.

An unusual source of an essential element was recently identified. Residential coal combustion that can cause severe health problems [20] may help to prevent Iodine Deficiency Disorders (IDD) in northwestern Guizhou Province, P.R. China [21]. The coals from this region have anomalously high iodine contents $(\sim 8 \mathrm{ppm}$ versus $\sim 1 \mathrm{ppm}$ for the world average). IDD is rare in the northwest part of the province where coal is plentiful and people use it to cook, heat their homes, and dry crops hanging from the rafters. In the southeastern part of the Province where wood is the primary fuel, IDD is endemic. Inhalation of iodine volatilized by the coal combustion and ingestion of foods enriched in iodine by drying over the high-iodine coal fires may be providing sufficient iodine to ward off the goiter, cretinism, and mental retardation caused by IDD.

\section{Pharmaceuticals and Health Care Products}

Most people would readily agree that 'minerals' are essential for their health and wellbeing. They are, of course, referring to the essential elements (calcium, potassium, sodium, etc.) that are required for good health and not to minerals in the strict sense. Minerals are defined as a naturally occurring crystalline solid with a definite but not fixed chemical composition [22]. Minerals are the fundamental building blocks of rocks, are a major component of all soils, and are the ultimate source of the essential elements. The term mineral as used in nutrition is actually a misnomer resulting from the fact that the essential elements were derived from minerals; but minerals in their own right have many beneficial health properties.

They are used in a wide range of everyday healthcare products. Common products such as Kaopectate (kaolin), Tums (calcite), Milk of Magnesia (magnesite), talcum powder (talc), toothpastes (quartz, rutile), anti-perspirants (bauxite), calcium supplement (ground up coral) all rely on minerals for their beneficial health properties. In addition, various clays are used in antacids, gypsum in Plaster of Paris. Pumice is the abrasive in natural pumice stone and Lava soap, extracts from coal are used in dandruff shampoos, fluorine in fluoridated water and toothpastes, and salt (halite) has been used as an antibacterial agent and as a food preservative for millennia. Epsom salt (epsomite) is found in most every household. Baking soda (trona) is a wellknown antacid and is also used intravenously (Figure 3a-h)

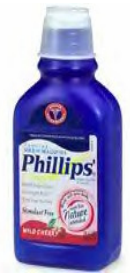

(a)

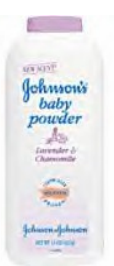

(e)

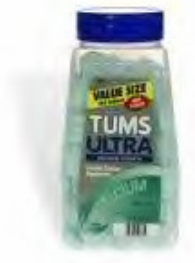

(b)

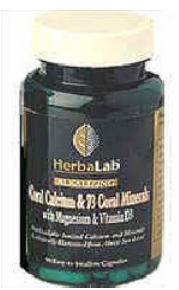

(f)

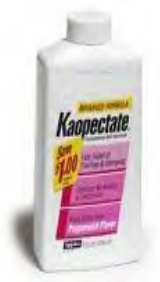

(c)

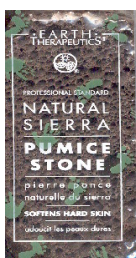

(d)
Figure 3: Minerals in everyday use. (a) Milk of magnesia, (b) Tums antacid, (c) Kaopectate, (d) natural pumice stone, (e) baby powder, (f) calcium supplement, (g) epsom salt, and (h) baking soda.

**Note: Illustration of these products does not constitute an endorsement.

Clays, the mineral group most widely used, and likely the longest used for heath care by both humans and animals, deserves special recognition [18]. One of the most important life saving uses of clay is its curing effect of buruli ulcers or flesh eating disease [23].

Zeolites have become a valuable medical resource. QuickClot (Figure 4), a product not available to the public at this point, has saved many lives with its blood coagulating properties. Emergency personnel and the military have it readily available. Heavy bleeding that occurs when femoral arteries are severed, can be stopped by ground up and sterilized zeolite [24]. Furthermore, studies are under way to confirm zeolite's affinity for radionucleides. Zeolites are already being used in low level nuclear radiation clean ups and are now being tested on humans to counter the effects of nuclear radiation exposure. Clinical trials are being conducted to investigate zeolite's anticancer properties [25].

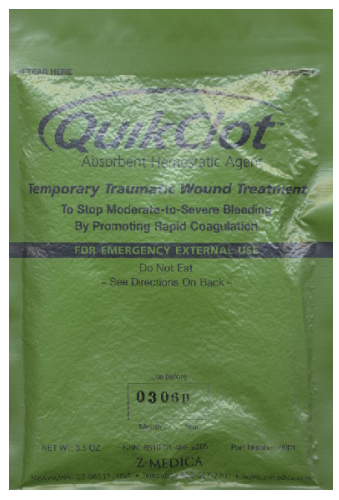

Figure 4: Ground up zeolite sold as Quick Clot 
Elements such as arsenic (Trisenox), mercury (mercurochrome, dental amalgam), boron (boric acid), selenium (dandruff shampoos), sulfur (drugs), barium (enemas, X-radiography), bismuth (Pepto Bismol), zinc (skin ointments), are the active ingredients in various drugs and pharmaceuticals. Some of the more exotic elements such as cesium, lithium, indium, samarium, gold, platinum, titanium and gallium, are used in an ever increasing array of sophisticated medical treatments and products (Figure 5).

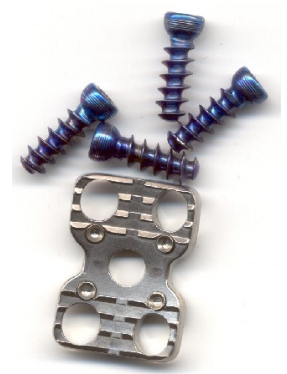

Figure 5: Surgical titanium plate and screws

While modern day America uses a few common minerals for medical purposes, other countries manufacture tons of pharmaceuticals using a variety of minerals and fossils [26]. More than ninety minerals, mineraloids, and rocks have been used for beneficial purposes with clay minerals leading the list, followed by quartz, amber, hematite, pearl, and malachite. Various illnesses and maladies have been treated with these earth materials, such as malachite and clays for infections, clays and pearls for gastrointestinal problems, and amber for alcoholism and to strengthen the immune system.

In ancient cultures the only available healing materials came from plants, animals, or minerals. Often the color of a mineral was believed to be related to the condition of an illness such as blood disorders being treated with a red mineral like hematite or ruby. Reasons for use of these earth materials range from actual effectiveness to the placebo effect.

Little research exists as to the actual curative and palliative qualities of minerals. However, the actual healing signature of one mineral that had been used for over 5000 years [27] was demonstrated in an in-vitro experiment. The purported anti-microbial properties of malachite were verified in a preliminary study with Staphylococcus aureus and Pseudomonas aeruginosa (Limpitlaw, unpublished data). This study showed that knowledge of healing properties of certain minerals existed and was utilized for millennia.

\section{Hot Springs and Related Geologic Phenomena}

Visiting hot springs and thermal baths for prevention and cure of a variety of illnesses, once popular in the USA, has fallen out of favor. This practice, however, is still popular in many other cultures. For example, in some European countries, going to a hot springs "cure" is included in medical insurance.

The study of the therapeutic benefits of naturally occurring mineral waters is known as balneology. In the
United States, this science is not well known, and is seldom practiced. However, throughout Europe and Japan, balneology and hot springs therapy is very much a part of routine medical care. Medical prescriptions are given by licensed doctors for the treatment of a wide range of conditions, and utilizing mineral waters as a part of preventative medicine is widely recognized and encouraged.

Advocates claim a large number of health problems can be cured by hot spring therapies. In Japan nine different chemical classes of hot springs have been recognized (simple, chloride, hydrogen carbonate, sulfate, carbon dioxide, iron, sulfur, acid, and radioactive).

Each class of hot spring is reputed to be effective in treating a wide range of health problems such as burns, hypertension, diabetes, gout, muscle aches, hemorrhoids, etc. (Mio Takeuchi, 2002, personal communication).

There appears to be little in the way of epidemiological support for such claims in the U.S. medical literature. A brief review of the National Library of Medicine abstracts of articles dealing with the therapeutic effects of hot springs revealed that most authors are from Japan. Other authors were from Germany, Turkey, China, Portugal, Greece, and Israel. The one article by a U.S. author reported on the historic use of hot springs to effectively treat venereal disease.

In addition to hot springs, geologic materials such as mud and sand have been used for therapeutic purposes. The therapeutic powers of Dead Sea black mud are mentioned in the Bible [28] and the mud is currently marketed worldwide. Beach sand baths in Porto Santo Island, Portugal are popular therapeutic practice. Gomes and Silva (personal communication, 2004) believe that essential elements in the carbonate and clay rich sands are incorporated into the bodies of the people covered by the sand by percutaneous mechanisms.

\section{Talismans and Amulets}

Talismans and amulets, commonly naturally occurring crystals, are believed by some to have positive health effects but, unlike the rock-derived pharmaceuticals, do not have scientifically proven health benefits. Talismans have been used for thousands of years and were believed to ward off evil and heal certain medical conditions. Geinger [29] identifies the unique spiritual, emotional, mental, and physical healing powers of nearly 100 rocks and minerals.

Since 1996 a scientific group in Germany has been doing empirical research on the health effects of crystals. Seventy different study units are investigating four crystals each year. As of July 2004, 40 different minerals had been tested. Their findings are published in a magazine called Opalitho. All reports include physical, spiritual, and emotional effects [30].

A recent survey on a college campus found that the student populations coming from tribal backgrounds such as Native Americans, Hawaiian, and Polynesian all have standing traditions of using talismans and amulets [31]. These traditions are being continued to this day.

Finally, it is an undisputed fact that a certain group of minerals exert wonderfully positive effects when presented to another person - these minerals are commonly called gems. 


\section{Conclusions}

The health benefits derived from geologic materials and geologic processes are commonly ignored in formal treatises, seminars, and research agendas. However, the list of benefits is extensive, varied, and often significant. Moreover, there still exists an exciting potential for finding novel health benefits of geologic materials and processes.

\section{References}

1. Skinner, H. C. W.; Berger, A. R., editors: Geology and Health -Closing the Gap. Oxford Press, Oxford, 2003, 179 p.

2. Komatina, M. M.: Medical geology - Effects of Geological Environments on Human Health. Developments in Earth \& Environmental Sciences, V. 2, Elsevier, Amsterdam, 2004, 488 p.

3. Selinus, O.; Alloway, B.; Centeno, J. A.; Finkelman, R. B.; Fuge, R.; Lindh, U.; Smedley, P.: Essentials of Medical Geology. Elsevier, Amsterdam (in press).

4. Berger, A.; Selinus, O.; Skinner, C.: "Medical Geology" - an emerging discipline. Episodes 2001, Vol 24, No 1.

5. Bowman, C.; Bobrowski, P. T.; Selinus, O.: Medical Geology: New relevance in the Earth Sciences. Episodes, 2003, Vol 26, No 4, 270-278.

6. Bunnell, J. E.: Medical geology: Emerging Discipline on the Ecosystem-Human Health Interface. EcoHealth 2004, 1, 15-18.

7. Ceruti, P.; Davies, T.; Selinus, O.: GEOMED Medical Geology, the African Perspective. Episodes, 2001, Vol. 24 No 4.

8. Dissanayake, C. B.; Chandrajith, R.: Medical geochemistry of tropical environments. Earth Science Reviews 1999, 47, 219-258.

9. Earthwise: Geology and health. British Geological Survey. 2001, Issue 17.

10. Selinus, O. S.: Medical Geology: an emerging speciality. Terrae, 2004, Vol 1(1), A1-A8

11. Finkelman, R. B.; Skinner, C. W.; Plumlee, G. S.; Bunnell, J. E.: Medical Geology, Geotimes, 2001, Vol. 46, no. 11, p. 20-23.

12. Dissanayake, C.: Of stones and health: Medical geology in Sri Lanka. Science, 2005, vol. 309, p. 883-885.

13. Natural Science and Public Health - Prescription for a better Environement. Abstracts from a conference on April 1-3, 2003, Reston Virginia, convened by the U.S. Geological Survey (USGS). Open File Report 03-097, U.S. Department of the Interior, USGS.

14. Limpitlaw U. G.: The medical uses of minerals, rocks, and fossils. Geological Society of America 2004 Annual Meeting, Abstracts with Programs, Abstract 48-5, 2004, Vol. 36, No. 5, p.130.

15. Min, S. J.: Lost in Translation: Journal of Science and Spirit, Nov Dec 2004, Washington, DC, Heldref Publication, 2004, p. 36-41.

16. Abrahams, Peter W.: The involuntary and deliberate (geophagy) ingestion of soil by humans and other members of the animal kingdom. In, Essentials of Medical Geology, Selinus, et al., eds. Elsevier, N.Y. 2005, p. 435-458.

17. Price, W. A.: Nutrition and Physical Degradation. Sixth Edition. The Price-Pottenger Nutrition Foundation, Inc., La Mesa, CA. 2000, 524 p.

18. Reinbacher, R.: Healing Earths: The third leg of medicine: Canada, York University, Toronto, 2003, 244 p.

19. Knishinsky, R.: The Clay Cure, Healing Arts Press, Rochester, VT. 1998, 104 p.

20. Finkelman, R. B.; Orem, W.; Castranova, V.; Tatu, C. A.; Belkin, H. E.; Zheng, B.; Lerch, H. E.; Maharaj, S. V.; Bates, A. L.: , Health impacts of coal and coal use: possible solutions. International Journal of Coal Geology, 2002, Vol. 50, p. 425-443.

21. Wang, Binbin; Finkelman, Robert B.; Belkin, Harvey E.; Palmer, Curtis A.: A possible health benefit of coal combustion. Abstracts of the $21^{\text {st }}$ Annual Meeting of the Society for Organic Petrology, 2004, Vol. 21, p. 196-198.

22. Hurlbut, Jr., C. S.: Dana's Manual of Mineralogy. $17^{\text {th }}$ Edition. J. Wiley \& Sons, N.Y., 1961, 609 p.

23. De Courssou, L. B.: Preliminary studies of debridement using clay materials on Mycobacterium ulcerans infections and ramifications: Geneva, Switzerland, presented at the $5^{\text {th }}$ WHO Advisory Group Meeting on Buruli Ulcers, burulibusters.com 2002.

24. Alam, H.; Zheng, C.; Jaskille, A.; Querol, R.; Koustova, K.; Inocencio, R.; Conran, R.; Seufert, A.; Ariaban, N.; Toruno, K.; Rhee, P.: Application of a zeolite hemostatic agent achieves $100 \%$ survival in a lethal model of complex groin injury in swine: The Journal of Trauma, Injury, and Critical Care, 2004, Vol. 56, p 974-983.

25. Pavetic, K.; Hadzija, M.; Pavelic, J.; Katiz, M.; Kralj, M.; Bosnar, M. H.; Kapitanovic, S.; Poljak-Blazi, M.; Stojkovic, R.; Subotic, B.: Natural zeolite clinoptilolite: new adjuvant in anticancer therapy: Journal of Molecular Medicine, October 2000, published online.

26. Aschoff, J.; Tashingang, T. Y.: Tibetan Jewel Pills, the Rinchen Medicine: Ulm, Germany, Fabri Verlag, 2001, 139p.

27. Nunn, J. F.: Ancient Egyptian Medicine: University of Oklahoma Press, Norman, OK, 1996.

28. Abdel-Fattah, A. N.: Dead Sea black mud: Medical geochemistry of a traditional therapeutic agent. Geological Society of America 2004 Annual Meeting, Abstracts with Programs, 2004, Vol. 36, No.5. Abstract 7-7, p. 25.

29. Gienger, M.: Crystal Power, Crystal Healing: The Complete Handbook. Translated from German. Sterling Publishing Co., NY, 2003, 416 p.

30. Opalitho, Die Zeitschrift des Steinheilkunde E.V., Fronreute, Germany, Druckerei Speh GmBH. 2005,

31. Limpitlaw, U.: The Palliative and Curative uses of minerals, fossils, and rocks: University of Northern Colorado, Greeley, CO. Unpublished data, 2005. 